Article

\title{
Long-Term Projection of Renewable Energy Technology Diffusion
}

\section{Tadeusz Skoczkowski, Sławomir Bielecki *(D) and Joanna Wojtyńska}

Faculty of Power and Aeronautical Engineering, Warsaw University of Technology, PL 00-665 Warsaw, Poland; tadeusz.skoczkowski@pw.edu.pl (T.S.); wojtynska.joanna@gmail.com (J.W.)

* Correspondence: slawomir.bielecki@pw.edu.pl

Received: 6 October 2019; Accepted: 5 November 2019; Published: 8 November 2019

check for updates

\begin{abstract}
The EU aims at increasing the use of renewable energy sources (RES), mainly solar-photovoltaic (PV) and wind technologies. Projecting the future, in this respect, requires a long-term energy modeling which includes a rate of diffusion of novel technologies into the market and the prediction of their costs. The aim of this article has been to project the pace at which RES technologies diffused in the past or may diffuse in the future across the power sector. This analysis of the dynamics of technologies historically as well as in modeling, roadmaps and scenarios consists in a consistent analysis of the main parameters of the dynamics (pace of diffusion and extent of diffusion in particular markets). Some scenarios (REMIND, WITCH, WEO, PRIMES) of the development of the selected power generation technologies in the EU till 2050 are compared. Depending on the data available, the learning curves describing the expected development of PV and wind technologies till 2100 have been modeled. The learning curves have been presented as a unit cost of the power versus cumulative installed capacity (market size). As the production capacity increases, the cost per unit is reduced thanks to learning how to streamline the manufacturing process. Complimentary to these learning curves, logistic S-shape functions have been used to describe technology diffusion. PV and wind generation technologies for the EU have been estimated in time domain till 2100. The doubts whether learning curves are a proper method of representing technological change due to various uncertainties have been discussed. A critical analysis of effects of the commonly applied models for a long-term energy projection (REMIND, WITCH) use has been conducted. It has been observed that for the EU the analyzed models, despite differences in the target saturation levels, predict stagnation in the development of PV and wind technologies from around 2040. Key results of the analysis are new insights into the plausibility of future deployment scenarios in different sectors, informed by the analysis of historical dynamics of technology diffusion, using to the extent possible consistent metrics.
\end{abstract}

Keywords: photovoltaics; wind energy; energy projection; learning curves; logistic curves

\section{Introduction}

Investments in the power sector are characterized by high capital intensity and a long payback periods. At present, the development of certain generation technologies depends on the energy policy linked to the global climate policy. Different energy technologies are supported or blocked by local, international and global authorities. Some policy makers may have different or even opposed opinions which, in consequence, create additional difficulties for the market. Therefore, there are not only technological and economical aspects which should be considered while forecasting the development of each technology, but also social ones since organized groups of local people can efficiently stop or at least postpone new investments.

Increasing the share of renewable technologies like PV and wind sources results from the EU's efforts to implement the adopted climate policy limiting the use of fossil fuels. Scenarios for the 
development of these technologies are in line with the upward trend. Scenarios developed by renewable energy organizations are based on the ambitions and interests of their members and can serve as a reference point for decision-makers in energy policy making.

Renewable energy technologies differ in performance, maturity level and cost-efficiency ratio but each technology has its individual potential. This variety made it fundamental to support them with targeted actions. In addition, distinctive elements that could foster global industrial competitiveness will be considered. The EU is going to support various technologies providing balance and sustainability at the highest possible level [1]. The short-term predictions until 2020 show a moderate increase for RES consumption with a declining pattern for fossil and nuclear sources in Europe, while for the US one predicts a mildly positive trend both conventional and renewable-oriented, whereas for China and India RES consumption will moderately increase and consumption from conventional sources is predicted to increase considerably [2].

Many examples from the power technology markets demonstrate the need for a dynamic government intervention in the market over several decades to help the ride down of the learning curve [3]. For example, governmental support may have strong effects on price reductions of wind turbines. While feed-in tariffs clearly stimulate the expansion of new capacity, it may also stimulate free-rider behaviour and cause stagnation of prices [4].

One of the major challenges Europe will face in the coming decades is creating a secure, efficient and clean energy system. It is supported by the Horizon 2020 under the theme "Secure, Clean and Efficient Energy". To make it happen, research and innovation is focused on the development of cost-effective and resource-efficient low carbon energy sustainable solutions with a significant role of domestic resources in the energy mix which would lead to the increase of energy security of power supply.

The development and diffusion of RES technologies is, therefore, expected. The concept of diffusion can be used to assess the degree of development. According to Rogers, one of the originators of diffusion of innovation theory, diffusion is the process by which an innovation is distributed to the members of a social system through certain channels over time [5].

Different models of describing the expected development of technology can be found in the literature. This issue involves the use of econometric models, statistics, management theory, communication studies, and refers to technical, economic, social and political aspects. The key innovation diffusion models have been developed since 1970's with the main categories of modification of these models classified as [6]: generalizing to consider the diffusion of successive generations of technology, also to consider at different stages of diffusions in different countries, and a marketing variables introduction in the parametrization.

The paper is structured as follows: In Section 1 the importance of the ability to model diffusion of RES technologies for projection of energy system in the long-term horizon is briefly reviewed. PV and wind technologies have been selected for further analysis. Section 2 addresses the overview of literature on diffusion modeling of RES technologies. To describe the diffusion of innovation, various models based on macroeconomic models are used. In Section 3 the objective of the paper is set-to project the pace at which RES technologies diffused in the past or may diffuse in the future across the power sector. Some scenarios of the development of selected power generation technologies in the EU till 2050 are compared. We introduce the two metrics. Section 4 presents the application of learning curves for modeling the two chosen RES technologies. A logistic function for diffusion visualization is dealt in Section 5. Technology development shown by S-shaped logistic curves for EU-28 are compared with the reference scenarios of REMIND and WITCH models. The discussion of the results is offered in Section 6. Section 7 covers the main conclusions, limitations and proposals for future research. It is also commented on how the integration of power systems and sectoral spillovers had been included in previous modeling and scenario narratives. 


\section{Overview of Selected RES Technology Diffusion}

The modeling of energy transitions should enable a quantitative description of transition in the technology domain and also in the market, institutional, and social domains. Concepts from the sustainable transition literature can assist to identify important mechanisms and variables within these areas [7]. To describe the diffusion of innovation, various models based on macroeconomic models are used. For example, a diffusion model integrating agent-based modeling for RES energy deployment was established and presented in [8].

Two main approaches can be used to present diffusion of a specific technology. One, presenting the expected progress of technology dissemination in time, and the other based on the presentation of the learning effect from experience. The first approach analyzes technological cycles and predicts when the saturation of innovations occurs. A useful tool used by researches is the S-curve model $[9,10]$. The second approach uses a learning curve concept. The learning curve refers to the cost reductions of a standardized product within a single firm, while an experience curve may also describe cost reductions of non-standardized products on a global, regional or national level [11]. Although today many authors use the term "learning curve" as a synonym for "experience curve" [12,13].

\subsection{Learning Curves}

In [4] examples of the main areas and levels of using learning/experience curves are listed:

- Company level-project future costs, formulate corporate strategy;

- National policy — evaluate the effects of past subsidies ( $R \& D$, investments), future investments required to a certain price level until a technology can compete with conventional equivalent;

- Global scenarios for selected technology development;

- Energy and climate change models—endogenize technological learning and associated cost reduction of RES technologies.

A learning curve expresses some useful correlations and the learning involves, like sampling of potentially cost-reducing processes indicating technological, managerial, or behavioral alternatives to pending operations. Such a model is a tool for assessing and designing a strategy or policy [3] and can be used to calculate investments needed to get a technology down to a competitive level, and the model may be necessary to diffuse it on a large scale in the market. Learning curves deliver a phenomenological description of the connections between different values e.g., cumulated production and past costs and are useful for the estimation of future cost reductions by simple extrapolation. A rich review of learning curve models used in production economics was conducted in [14].

The learning curve approach is extensively applied to energy supply technologies (RES as well as non-RES) in order to quantify potentials for cost or price decline [15]. Learning curve is a popular tool used for forecasting costs of RES technologies in integrated assessment models [16]. Based on the learning curves, many analysts state that policy intervention in order to accelerate learning investment will help the development of new RES technologies and that the resulting costs of future reduction will be much lower than simple estimations that do not consider the learning dynamics [17].

It was noted that for large-scale and highly complex generation technologies, the experience curve does not appear to be a useful tool for explaining cost changes over time [12]. In [16] a formal discussion was conducted on the learning curve application, limitation and related assumptions. According to the authors of [16], the most problematic issues are the absence of any effect of technology cost on its demand and the ability of integrated assessment models to predict the determinants of cumulative capacity; it was shown, though, that specified assumptions can be tempered by modifying the traditional econometric method used to the learning curve estimation.

The first comprehensive review of learning curve analyzes for energy demand technologies was conducted in [15]. In [12] the reviews presented the experience (learning) curve theory with empirical evidence in power generation technologies. In [18] the use of learning curves for the description of cost reduction of energy technologies was investigated. 
In [18] it was demonstrated that for many power generation technologies, like wind turbines, the potential for growth is typically limited to only a couple of doublings with respect to the currently installed capacity. For other power technologies similar qualitative estimations regarding their growth potential can be made, which implies that it might not be more generally possible to detect cost reductions once they come close to a technology-specific upper bound for deployment.

In [1] the learning curve of balance-of-system costs in PV for more than 20 countries via an extensive dataset was estimated. It was shown that a number of cost reduction opportunities exist and require only a little support of financial policy. These include stimulating market competition among installers, legal process standardization and adopting installation schemes. In [19] the cost of PV modules out to 2020 was predicted using models of learning curves and the implications of the costs of electricity from described PV modules.

The analysis based on the Colombian case presented in [20] indicated that PV system cost is not necessarily an important element in the diffusion of PV systems when grid parity is attained. Moreover, it was noticed that the implementation of policies is an imminent obligation for legislators because the lack of policy may cause negative effects on the market, risking market stability or its sustainability. The case of South Korea regarding learning the curve theory for PV power generation was analyzed in [21].

The first study of learning curves with the use of actual wind power generation as an output measure, turbine size and unit turbine costs between 2005 and 2012 during the rapid expansion phase of China wind power industry was presented in [22]. The Chinese case of wind power demonstrates that complement deployment policies do not necessarily lead to technological learning and the market expansion is possible in the absence of carefully designed policies of innovation.

In [17] the authors concluded that the learning curve cannot separate the effects of price and technological change, neither can it reflect a continuous and qualitative change of conventional or emerging energy technologies, and it cannot help to determine the time paths of technological investment, missing the crucial R\&D activity role in driving technological change. The learning curve indirectly assumes that technology can change instantly with installed capacity, which is doubtful.

There are doubts whether learning curves are a proper method of representing technical change due to various uncertainties. Their results have not been sufficiently examined yet. Uncertainties in technology experience curves are extensively discussed by Yeh and Rubin [23]. The main questionable variable is the learning rate parameter, but also the functional form determining the shape of a curve. The most widely adopted is a one-factor, log-linear experience curve-it can easily be used in general equilibrium and partial equilibrium models which are based on the Mixed Integer Programming. An alternative to the conventional learning curve is a deviation from log-linearity at the beginning and the end of the entire development. Another example is an S-shape curve which also creates some doubts as it disregards the influence of political, social and economic factors which are not taken into consideration within learning curves.

\subsection{Technology Diffusion}

A study of RES (non-hydro) technology diffusion in 108 developing countries observed between 1980 and 2010 was conducted in [24]. The authors found a weak support for positive influence of the Kyoto Protocol on non-hydro RES technology diffusion. Also, the authors of diffusion analysis presented in [25] suggested that in Brazil, Russia, India, China and South Africa (BRICS) countries the Kyoto mechanisms do not create proper incentives for the use of RES technologies. The analysis of the diffusion determinants of RES in 26 the Organization for Economic Co-operation and Development (OECD) countries between 1990 and 2013 with a specific focus on modern fossil technologies was conducted in [26].

In [27] an integrated approach for the RES technologies diffusion was considered regarding technology, conversion, availability of sources, cost and policy. The authors pointed out to the continuing barriers to the large-scale adoption of RES energy in India. It was underlined that the lack 
of large-scale success does not imply the impropriety of the technology and rather suitable efforts are required to create an environment to promote the adoption of such a technology.

A German case of RES energy diffusion focusing on the specific role of the firms' regional environment was analyzed in [28]. It showed that for energy policy, in addition to (hard) regulation measures like energy law or emission trading system, also soft instruments such as measures to encourage environmental and social responsibility of managers or environmental awareness of the population, may play a role in the reinforcement of the RES diffusion.

In [29] one discussed the flexibilization of power networks as a means of RES diffusion and it was noted that the convergence of interests among wind and PV technology suppliers supports the idea that pertinent interactions are already in place. The policies (industrial, climate and energy) should thus be inspired according to a systemic perspective and a future research should expand the empirical analysis of such interactions [29].

A logistic curve of improving performance can better describe the cost reductions in energy technologies when it is modified to include R\&D activity as a driving variable. An investment in $R \& D$ can accelerate the process of technological development and conversely.

The traditional diffusion literature fits S-shaped diffusion curves (like the logistic function) to diffusion measure [30]. In [31] the analysis of efficient market diffusion of intermittent energies from RES was conducted as their capacity costs fell over time. An S-shaped pattern was found and it was presented how it can be traced back to the effects of intermittency. It becomes efficient to add RES to the generation system when their levelized cost of energy (LCOE) has fallen to that of fossil sources.

The four-parameter multi-cycle logistic growth curve models were used in [32] to perform a case study of energy production and consumption in the US to 2040. In [33] it was shown that at present wind and solar power demonstrates early signs of logistic growth despite high learning rates and energy return on energy invested particularly in the PV sector. A diffusion model based on the classic Bass diffusion theory, where the adoption rate is a function of awareness-raising campaigning and social interaction for the Colombian PV was also investigated in [34].

It may be concluded, that the logistic growth models have been developed since the 19th century for a model population [35], in the 20th century as a modeling tool for fuel energy production [32]. In [36] the use of single logistic curve and logistic component analysis was presented focusing on the coherence between model, data and interpretation. In technical applications logistic functions are used for example in modeling a dependence of technical or exploitation parameters, e.g., power curve for wind turbine in relation to wind speed [37].

\section{Problem Formulation}

Wind and solar have always featured in long-term energy scenarios, both from the Integrated Assessment Modeling (IAM) community, as well as other organizations such as the International Energy Agency ([38-41]). However, there are almost no scenarios that have foreseen a fast decrease in costs and rapid deployment over the last decade [42]. Creutzig et al. [42] find that the underestimation of PV growth can be traced back to the fact that models have overlooked public incentive schemes and rapid technological learning.

The variable RES, e.g., wind and solar, are an important option for the decarbonization of the power sector. These technologies have experienced deep cost reductions of more than 80 percent over the last decades, and seen unprecedented growth, with wind and solar capacity increasing 9-fold over the last ten years [43]. It is an open question whether or not future deployment will continue at this pace, or if system integration challenges will potentially slow down the transformation. Given the limited technology readiness of large-scale electricity storage, difficulties to expand transmission grids both between and within countries, as well as limited experience with market designs and regulations that incentivize flexibility provision, system integration challenges are clearly one of the key challenges for a fast low-carbon transformation of the power sector. 
The main three elements of technological development are: technology learning, especially learning by doing, corporate investment in R\&D and spillovers from research and development institutes.

The main aim of this article has been to project the pace at which RES technologies have diffused in the past or may diffuse in the future across the power sector. Models have been built to evaluate and describe the development of RES technology in the energy sector for PV and wind on the basis of available scenarios, outlooks and roadmaps for Europe. Projection of the trend in the development of energy generation technologies is needed especially for:

- economic and energy policy makers at all levels,

- investors, both those investing in new generation capacities in the power system and producers of equipment for power generation units,

- $\quad$ energy industry planners, analysts and researchers in the development of the industry.

This paper provides an expository research concerning the problem of predicting the development and diffusion of future energy generation technologies. The focus was on two promising technologies: wind and PV sources.

According to IEA [44], in 2050 in Europe with above 450 GW capacity in wind power, it will be possible to avoid emission of $462 \mathrm{Mt} \mathrm{CO}_{2}$ per year. The $4500 \mathrm{TWh}$ generated by $\mathrm{PV}$ in 2050 is expected to save $2.3 \mathrm{Gt}$ of $\mathrm{CO}_{2}$ emissions on an annual basis worldwide, almost twice that was predicted in the "BLUE Map scenario". It corresponds to approximately $5 \%$ of the total avoided $\mathrm{CO}_{2}$ emissions (48 Gt) from all technology areas projected in this scenario [45]. Wind power can generate a significant value for the country's economy through a supply chain investment and job creation. There is an increasing recognition of the ability of wind energy, along with other RES, to help spur innovation and thus a stable, long-term economic growth [46]. It is estimated that in the solar PV sector, in 2020, the total jobs per year factor (full-time equivalent) will reach 136,096 and Gross Value Added (GVA) per year will reach $6671 \mathrm{M}$ EUR in EU28 [47].

The data in Table 1 are from three different sources: $[41,44,48]$. It can be noticed that while the results for both IEA sources are quite similar, they clearly differ from the IRENA ReMap scenario. The reasons are that both IEA reports have been prepared by the same organisation within a year time difference. Therefore, predicted electricity generation for wind energy is very similar in the both report-over 5000 TWh onshore and over 2000 TWh offshore. The predictions differ in case of the solar PV generation-6400 TWh and 5100 TWh respectively. However, IRENA's scenario says that wind electricity generation will reach 18,000 TWh in 2050, which is over 10,000 TWh more than in the IEA's reports. It also contributes to higher percentage of global electricity generation- $36 \%$ compared to $17.8 \%$. It also exhibits a more optimistic approach towards solar PV-11,000 TWh generated which is twice as much as in the IEA roadmaps.

Table 2 presents the data from the [41,48-51]. It can be noticed that the expected world solar PV capacity in year 2030 is in the range $1200 \mathrm{GW}-1721 \mathrm{GW}$ based on the three different sources. What is interesting, IEA predicted in 2014 higher value than BP forecasts in 2018. From the WEO 2016 it can be read that the specific investment costs are twice higher for wind offshore technology (3000 USD $/ \mathrm{kW}$ ) than for wind onshore (1500 USD/kW). WEO predicts lower PV capacity in year 2030 than other considered scenarios, it also has lower investment cost for utility-scale solar modules-850 USD $/ \mathrm{kW}$. 
Table 1. World capacity, electricity generation and investment costs of solar PV and wind energy globally in year 2050 (sources of data: [41,44,48]).

\begin{tabular}{|c|c|c|c|c|}
\hline & Criteria & $\begin{array}{c}\text { Technology } \\
\text { Roadmap Solar } \\
\text { PV } 2014 \text { (IEA) }\end{array}$ & $\begin{array}{c}\text { Technology } \\
\text { Roadmap Wind } \\
2013 \text { hiRen Scenario }\end{array}$ & $\begin{array}{l}\text { IRENA ReMap } \\
\text { Scenario }\end{array}$ \\
\hline \multirow{3}{*}{$\begin{array}{l}\text { Wind } \\
\text { onshore }\end{array}$} & Capacity [GW] & & & 4924 \\
\hline & $\begin{array}{c}\text { Electricity } \\
\text { generation [TWh] }\end{array}$ & 5600 & 5100 & \\
\hline & $\begin{array}{l}\% \text { of global } \\
\text { electricity generation }\end{array}$ & $14 \%$ & $14 \%$ & \\
\hline \multirow{3}{*}{$\begin{array}{l}\text { Wind } \\
\text { offshore }\end{array}$} & Capacity [GW] & & & 521 \\
\hline & $\begin{array}{c}\text { Electricity } \\
\text { generation }[\mathrm{TWh}]\end{array}$ & 2400 & 2050 & \\
\hline & $\begin{array}{l}\% \text { of global } \\
\text { electricity generation }\end{array}$ & 0.06 & 0.065 & \\
\hline \multirow{3}{*}{ Wind total } & Capacity [GW] & & & 5445 \\
\hline & $\begin{array}{c}\text { Electricity } \\
\text { generation [TWh] }\end{array}$ & & 7150 & 18,000 \\
\hline & $\begin{array}{l}\% \text { of global } \\
\text { electricity generation }\end{array}$ & & $18 \%$ & $36 \%$ \\
\hline \multirow{5}{*}{ Solar PV } & Capacity [GW] & 4674 & & \\
\hline & $\begin{array}{c}\text { Electricity } \\
\text { generation [TWh] }\end{array}$ & 6400 & 5100 & 11,000 \\
\hline & $\begin{array}{l}\% \text { of global } \\
\text { electricity generation }\end{array}$ & $16 \%$ & $14 \%$ & $22 \%$ \\
\hline & Investment cost Utility-scale & 700 & & \\
\hline & $(\mathrm{USD} / \mathrm{kW})$ & 900 & & \\
\hline
\end{tabular}

Table 2. World capacity, electricity generation and investment costs of solar PV and wind energy globally in year 2030 (sources of data: [41,48-51]).

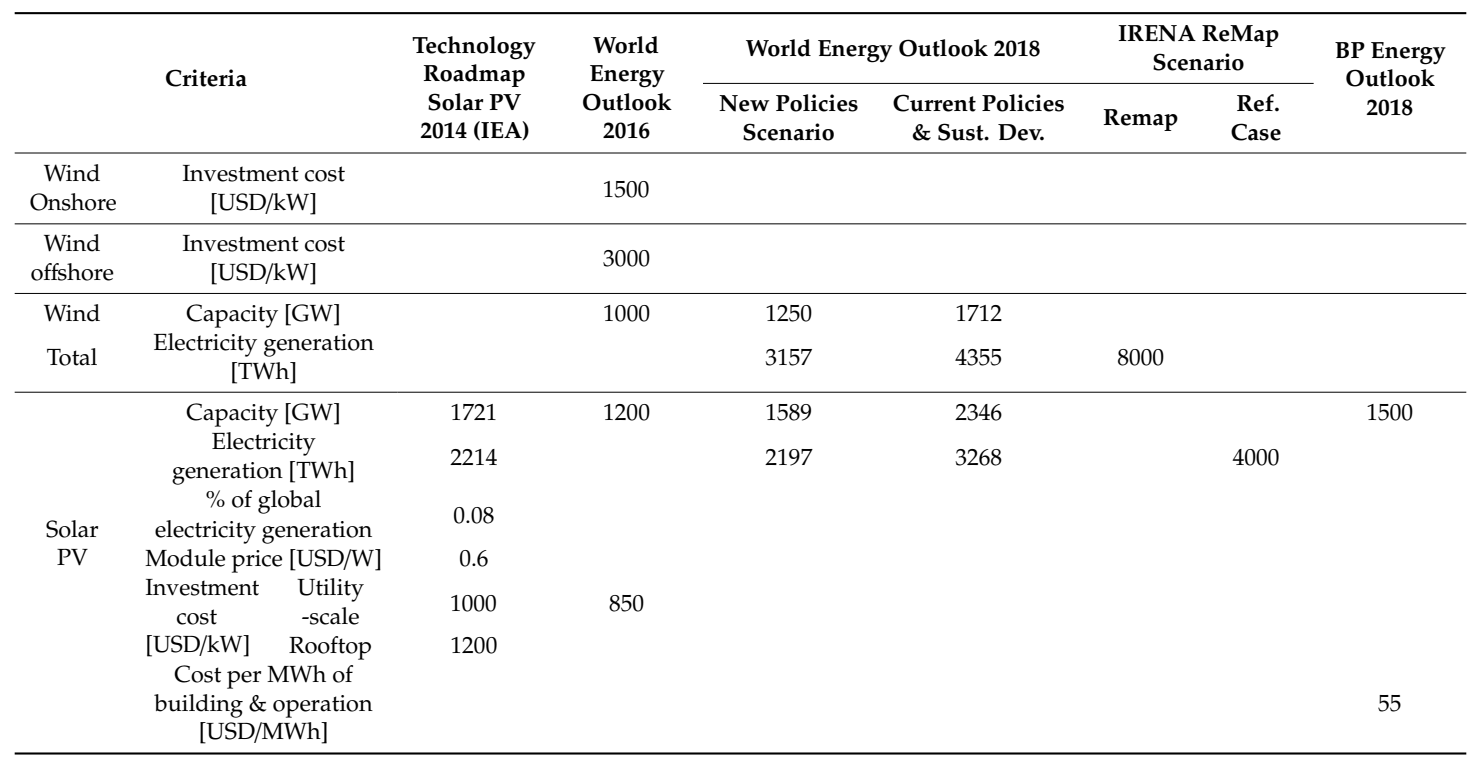

\section{Learning Curves}

The values describing learninig curves in this section are calculated from the basic formula of learning curve expressed by the Wright's law:

$$
C_{t}=C_{0}\left(\frac{x_{t}}{x_{0}}\right)^{b}
$$

where $C_{t}$-cost of a technology in time $t, C_{0}$-initial cost $(t=0), x_{t}, x_{0}$-cumulative production in time $t$ and initial (in time $t=0$ ) respectively, $b$-empirically observed learning rate parameter. 
This empirical law has been observed in many industries and for a wide range of technologies [52]. The learning rate $(L R)$ is the relative cost reduction from a doubling of cumulative production. It is used for calculating $b$ from (1):

$$
L R=1-2^{b}
$$

When applying one-parameter learning curves, the learning rate $(L R)$ is a powerful factor influencing the shape of it. Later, the learning curves for PV and wind generation technology have been compared by using historical data and values calculated from (1) for various initial costs. Learning rates are selected as mean values according to [53]: $23 \%$ for PV $12 \%$ for wind. The price history of silicon PV cells and costs wind electricity are assumed according to [54,55].

\subsection{PV Technology}

It is crucial, which data are taken as the input to (Table 3). In the case where the initial cost was taken as 40 USD (data from 1979), calculated values are much more similar to historical data than in the case with 9 USD cost (data from 1992). The differences for better results are higher at the beginnig, but for year 2004 it is already 1 USD, for 2011 it is 0.2 USD and for 2015, 0.3 USD. This means, that learning curve forecasts are not ideal, but they are very similar to reality (assuming that there will not be any unforseen disruptive innovations).

Table 3. Comparison of historical and calculated data for PV. Own work based on $[54,55]$.

\begin{tabular}{ccccc}
\hline \multirow{2}{*}{$x_{\boldsymbol{t}}[\mathrm{MW}]$} & \multicolumn{3}{c}{$\boldsymbol{C}_{\boldsymbol{t}}[\mathrm{USD} / \mathbf{W}]$} & \multirow{2}{*}{ Year } \\
\cline { 2 - 4 } & Historical & $\boldsymbol{C}_{\boldsymbol{0}}=\mathbf{4 0}$ USD & $\boldsymbol{C}_{\mathbf{0}}=\mathbf{9}$ USD & \\
\hline 100 & 9 & 12.927 & 9 & 1992 \\
900 & 7 & 5.645 & 3.93 & 2000 \\
5,000 & 4 & 2.957 & 2.059 & 2004 \\
60,000 & 1.4 & 1.159 & 0.807 & 2011 \\
200,000 & 1.08 & 0.736 & 0.512 & 2015 \\
\hline
\end{tabular}

The aproximated c-Si modules (solar PV technology) learning curve is shown in Figure 1.

It can be projected that in year 2020 the unit cost of c-Si module will be $0.466 \mathrm{USD} / \mathrm{W}$; it will decrease to $0.391 \mathrm{USD} / \mathrm{W}$ in 2030, then to $0.215 \mathrm{USD} / \mathrm{W}$ in 2040 and will finally reach the price of $0.202 \mathrm{USD} / \mathrm{W}$ in the middle of the 21st century. Of course, these forecasts did not predict any significant innovations- the development was assumed to conduct smoothly.

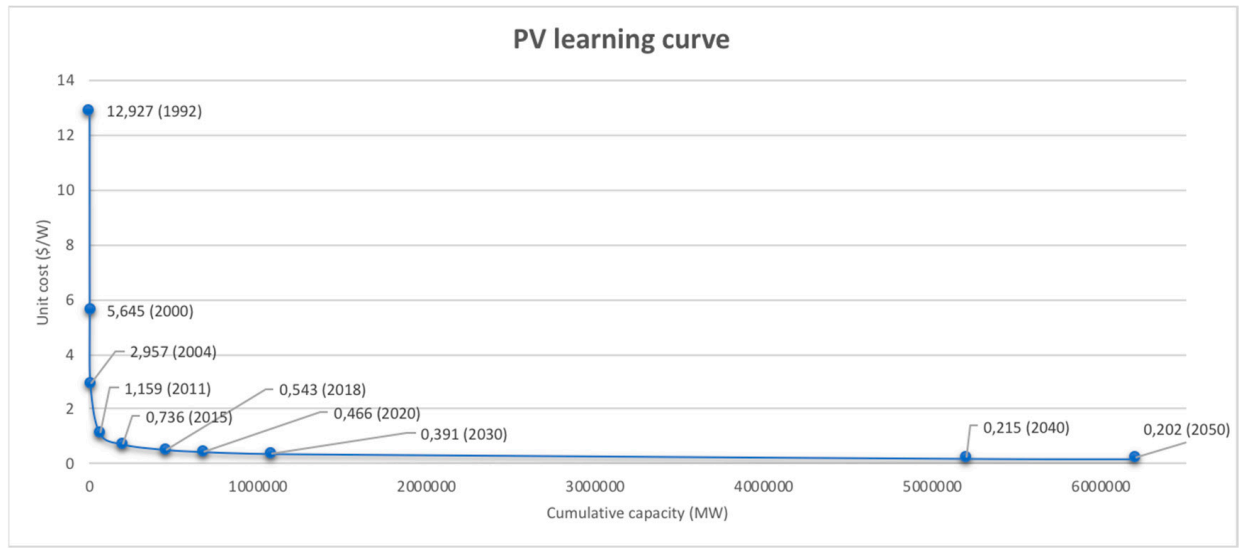

Figure 1. PV learning curve calculated from (1).

\subsection{Wind Technology}

The values used for generating the learning curve for wind technology represent the initial levelized cost of wind power of 600 USD/MWh for 1985 and 200 USD/MWh for 1990. From Table 4 
it can be concluded that, similarly to the PV case, the data put into (1) have to be appropriately selected. However, for the wind technology learning curve, the case where the initial levelized cost is 200 USD/MWh gives better fit to historical data than the earlier one. Except for the calculation made for year 2009, where the difference is 37 USD, the remaining values differ only by a few dollars, while for the previous example, the inaccuracy was more than 200 USD. Such errors (over 100\%) cannot be taken into consideration while forecasting the development of a technology. The chosen approximation is also not ideal but it shows the general character of learning curves for wind technology. For wind technology, the learning curve does not coincide so closely with the historical data as in the solar PV learning curve, but the trend is basically preserved.

Table 4. Comparison of historical and calculated data for wind power. Own work based on $[54,55]$.

\begin{tabular}{ccccc}
\hline \multirow{2}{*}{$x_{t}[\mathrm{MW}]$} & \multicolumn{3}{c}{$\boldsymbol{C}_{\boldsymbol{t}}[\mathrm{USD} / \mathbf{M W h}]$} & \multirow{2}{*}{ Year } \\
\cline { 2 - 4 } & Historical & $\boldsymbol{C}_{\mathbf{0}}=\mathbf{6 0 0}$ USD & $\boldsymbol{C}_{\mathbf{0}}=\mathbf{2 0 0}$ USD & \\
\hline 1600 & 200 & 550 & 200 & 1990 \\
6000 & 160 & 431 & 157 & 1995 \\
10,000 & 150 & 392 & 143 & 1999 \\
12,800 & 140 & 375 & 136 & 2000 \\
100,000 & 130 & 257 & 93 & 2009 \\
400,000 & 85 & 199 & 72 & 2014 \\
450,000 & 80 & 194 & 71 & 2015 \\
\hline
\end{tabular}

The final aproximated wind power learning curve is shown in Figure 2. Particular levelized costs are presented in correspoding years. While in 2018, the levelized cost for wind power is $66 \mathrm{USD} / \mathrm{MWh}$, it can be projected that in 2 years this value will fall to 64 USD/MWh. In 2030 the values are not significantly smaller-60 USD/MWh. However, because for the following years, huge investments in the wind power sector are expected, the levelized cost in 2040 will only be $45 \mathrm{USD} / \mathrm{MWh}$ and it will slightly decrease to $44 \mathrm{USD} / \mathrm{MWh}$ until year 2050. This scenario does not take into account some possible major innovations in wind power technology—therefore the increase is smooth.

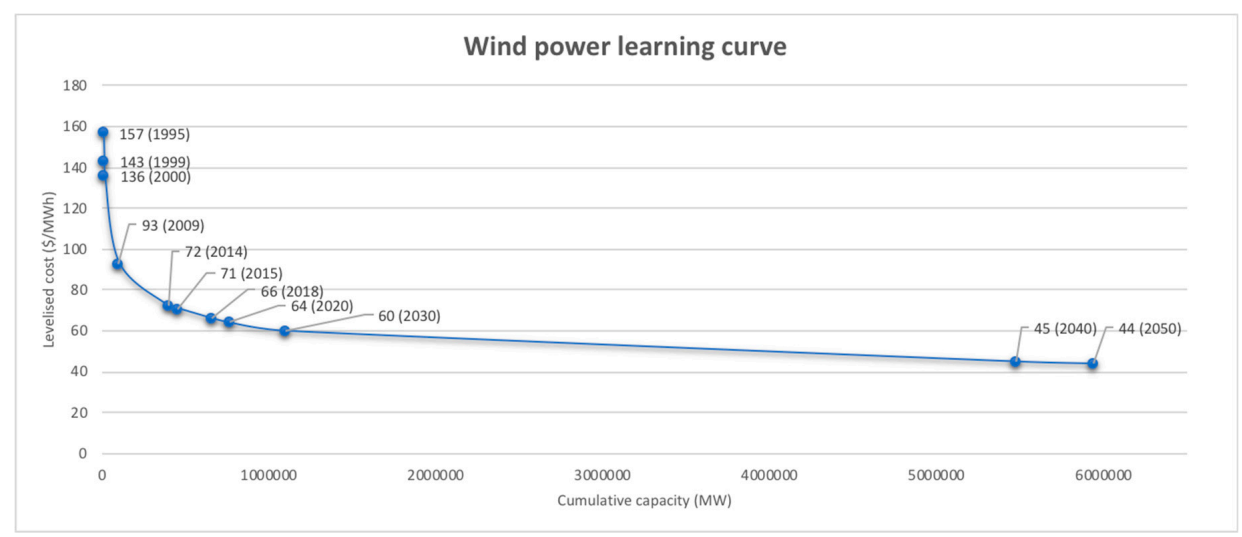

Figure 2. Wind power learning curve calculated from (1).

\section{Logistic Functions for Diffusion Visualization}

\subsection{Problem Description}

The number of the energy-economy models in use is large although only few are considered reliable and are commonly accepted by researchers and their outcomes are helpful to decision makers. This included for example the ADVANCE project models (REMIND and WITCH), PRIMES—-the model used, inter alia, for the Winter Package, the IEA's World Energy Model (WEM), and the Shared Socioeconomic Pathways (SSP) scenarios. The models differ so much that the comparison of their outcomes may be ambiguous (Table 5). 
Table 5. Models and scenarios gaps and inconsistences limiting the analyzes for power sector [56].

\begin{tabular}{|c|c|c|c|c|}
\hline Scenario/Roadmap & $\begin{array}{l}\text { Period Covered and Time } \\
\text { Interval }\end{array}$ & Metrics Used & Main Focus & Region \\
\hline WEM & $\begin{array}{l}2000,2015-2040 \\
5 \text {-year interval } \\
\text { No } 2020 \text { data }\end{array}$ & $\begin{array}{c}\text { Energy production in absolute values } \\
\text { (TWh/year) in PV and wind sources } \\
\text { Capacity in absolute values (GW) in PV and } \\
\text { wind sources } \\
\text { Data for wind-no distinction on off- } \\
\text { and onshore }\end{array}$ & $\begin{array}{l}\text { Projection on development of energy } \\
\text { generation technologies (New Policies } \\
\text { Scenario, Current Policies and } \\
\text { Sustainable Development Scenario) }\end{array}$ & European Union \\
\hline REMIND & $\begin{array}{c}\text { 2005-2100 } \\
\text { 5-year interval }\end{array}$ & $\begin{array}{c}\text { Energy production in absolute values (EJ/year) } \\
\text { in PV and wind sources } \\
\text { Capacity in absolute values (GW) in PV and } \\
\text { wind sources } \\
\text { Data for wind-no distinction on off- } \\
\text { and onshore }\end{array}$ & $\begin{array}{l}\text { Projection on development of energy } \\
\text { generation technologies across } 6 \text { version } \\
\text { of scenarios }\end{array}$ & European Union \\
\hline WITCH & $\begin{array}{c}2005-2100 \\
\text { 5-year interval }\end{array}$ & $\begin{array}{c}\text { Energy production in absolute values (EJ/year) } \\
\text { in PV and wind sources } \\
\text { Capacity in absolute values (GW) in PV and } \\
\text { wind sources }\end{array}$ & $\begin{array}{l}\text { Projection on development of energy } \\
\text { generation technologies across } 6 \text { version } \\
\text { of scenarios }\end{array}$ & World \\
\hline PRIMES & $\begin{array}{c}\text { 2005-2100 } \\
\text { 5-year interval }\end{array}$ & $\begin{array}{c}\text { Simulates EU's energy supply system. } \\
\text { It evaluates the potential of new technologies } \\
\text { by considering four types of factors: dynamics, } \\
\text { economic optimality, endogenous technology } \\
\text { learning \& maturity of technology and gradual } \\
\text { market diffusion which is influenced by costs } \\
\text { and risk perception }\end{array}$ & $\begin{array}{l}\text { Projects energy demand and supply } \\
\text { balances distinctly for } 45 \text { energy } \\
\text { commodities and forms, e.g., PV } \\
\text { electricity, wind on- and off-shore } \\
\text { Produces EU Reference Scenario for the } \\
\text { Winter Package }\end{array}$ & EU-28 \\
\hline WindEurope's 2030 Scenario & Target for 2030 & $\begin{array}{l}\text { Wind capacity in GW in Europe and share of } \\
\text { wind in EU's demand }\end{array}$ & $\begin{array}{l}\text { Forecast of wind onshore source } \\
\text { potentiality according to } 3 \text { scenarios } \\
\text { (low, central, high) }\end{array}$ & European Union \\
\hline $\begin{array}{l}\text { European Wind Energy } \\
\text { Association (EWEA) Wind } \\
\text { Energy Scenarios up to } 2030\end{array}$ & $\begin{array}{l}\text { 2007-2030 1-year interval, } \\
\text { targets for 2010, 2020, } 2030\end{array}$ & $\begin{array}{l}\text { Electricity production in TWh and installed } \\
\text { capacity in GW in wind (on- and off-shore) }\end{array}$ & $\begin{array}{l}\text { Projection of wind installation on- and } \\
\text { off-shore in Europe }\end{array}$ & EU-28 \\
\hline $\begin{array}{c}\text { IRENA (International } \\
\text { Renewable Energy Agency) } \\
\text { REmap2030 }\end{array}$ & 2015-2030 5-year interval & Cumulative PV capacity (GW) & Projection of PV sources development & World \\
\hline
\end{tabular}


The Regionalized Model of Investments and Development (REMIND) model [57] was developed as part of the Advanced Model Development and Validation for Improved Analysis of Costs and Impacts of Mitigation Policies (ADVANCE) project. It was a project funded by the European Union's Seventh Framework Programme (FP7). The World Induced Technical Change Hybrid (WITCH) model [58] is a dynamic model which combines the relations between technological, economic and climate change issues, it was developed at the European Institute on Economics and Environment in Milan, Italy.

Only REMIND and WITCH provide a wide range of available curves both for PV and wind technologies up to 2100 . The logistic curve model was used to approximate trends in capacity installed or electricity generation till 2100 . The presented curves for the both models refer to their reference scenario versions. The other models cover the period up to 2050 mostly due to the lack of reliable input data afterwards, e.g., political decision, technology perspective, reliable costs projections. Therefore, for such a long-term modeling the logistic curve (S-shaped) seems to be most suitable one. The S-shaped curve can be treated as an alternative to the conventional learning curve. In this one, the slow initial improvements are followed by more rapid improvement rate, after which an eventual leveling off occurs.

In the light of two models used in long-time modeling (REMIND V1.7 and WITCH 2016) technology development trends for EU-28 were compared and based on absolute values (energy generation and installed capacity) and their relative values calculated (the share of capacity and the share of energy generation).

The share of the installed capacity is the quotient of installed capacity in specific technology to the total installed capacity. The share in the total energy generation is a quotient of net electricity production from specific technology to the total net electricity production. Such factors:

- illustrate the effect of the operation and the effectiveness of using the technology,

- enable comparison of the intensity of generation development between technologies,

- allow to observe the trend of the technology options in the balance of energy production,

- allow to assess the significance of the technology in covering energy production,

- allow to evaluate the success in meeting the assumed share of the RES-target.

The selected S-shaped logistic curve is expressed by the following formula:

$$
f(t)=\frac{L}{1+e^{-k\left(t-t_{0}\right)}}
$$

where: $L$-saturation level, $k$-steepness of the curve, $t_{0}$ —curve midpoint.

In order to fit time series to the best-fitting logistic function, Matlab ${ }^{\circledR}$ file exchange fit_logistic version 1.9.0.0 has been modified to obtain a set of function parameters. Subsequent tables show the parameters of the estimating curve $\left(L, k, t_{0}\right)$ and the correlation coefficient (the Pearson factor) $r$ between row data and estimation by the logistic curve.

The Pearson correlation factor $r$ between approximation (logistic function) fit and data from scenarios, allows to assess matching of the value to the estimated function, according to the Guilford classification:

$|r|=1$ full classification,

$0.9<|r|<1$ almost full,

$0.7<|r| \leq 0.9$ very high,

$0.5<|r| \leq 0.7$ high,

$0.3<|r| \leq 0.5$ mediocre,

$0.1<|r| \leq 0.3$ weak,

$|r| \leq 0.1 \mathrm{dim}$. 
Hence, if $|r|<0.9$, the logistic function is not a proper model for estimation of technology market penetration dynamics.

5.2. Technology Development Shown by S-Shaped Logistic Curves for Europe (EU-28) According to the Reference Scenarios of Remind and Witch Models

\subsubsection{PV Technology}

Europe's PV technology development based on capacity is shown by the S-shaped curve with quite a stable beginning followed by a rapid growth. The capacity reached in 2100 predicted by REMIND is 4.9 TW while by WITCH is 1.6 TW. While Europe's PV capacity looks like it is uniformly rising and being still in the maturity level in year 2100, its share in total Europe's installed capacity is reaching the saturation level already in about 2070 (about 74\%-REMIND or 17\%-WITCH) (Table 6).

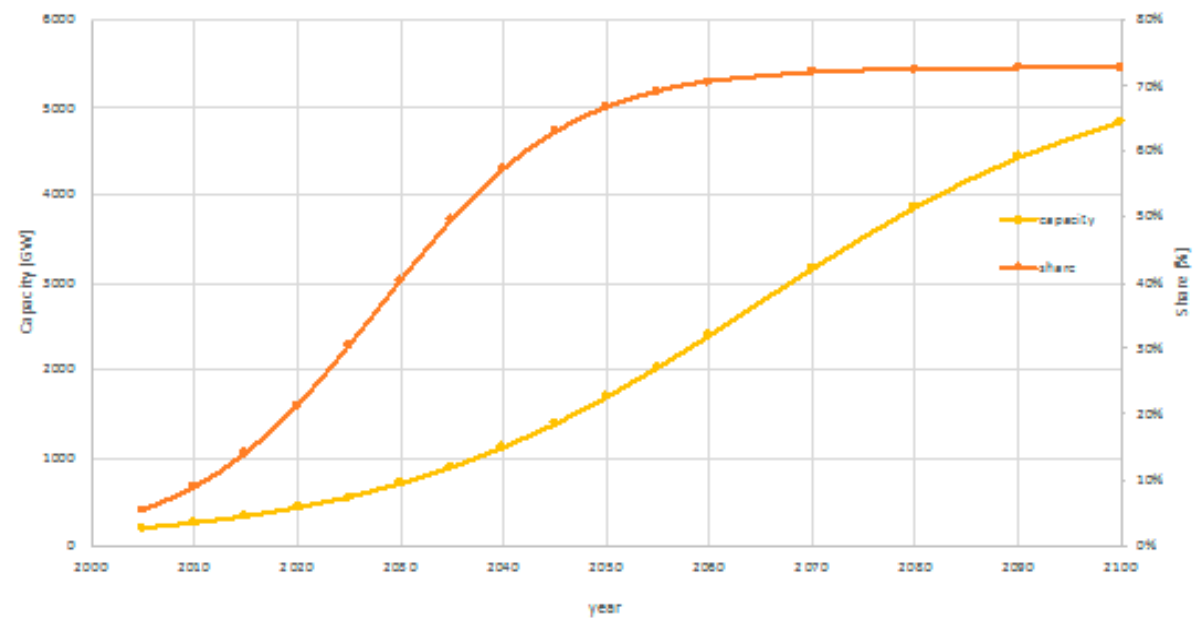

Figure 3. Europe PV technology capacity development based on the reference scenario of REMIND until the year 2100 (own work).

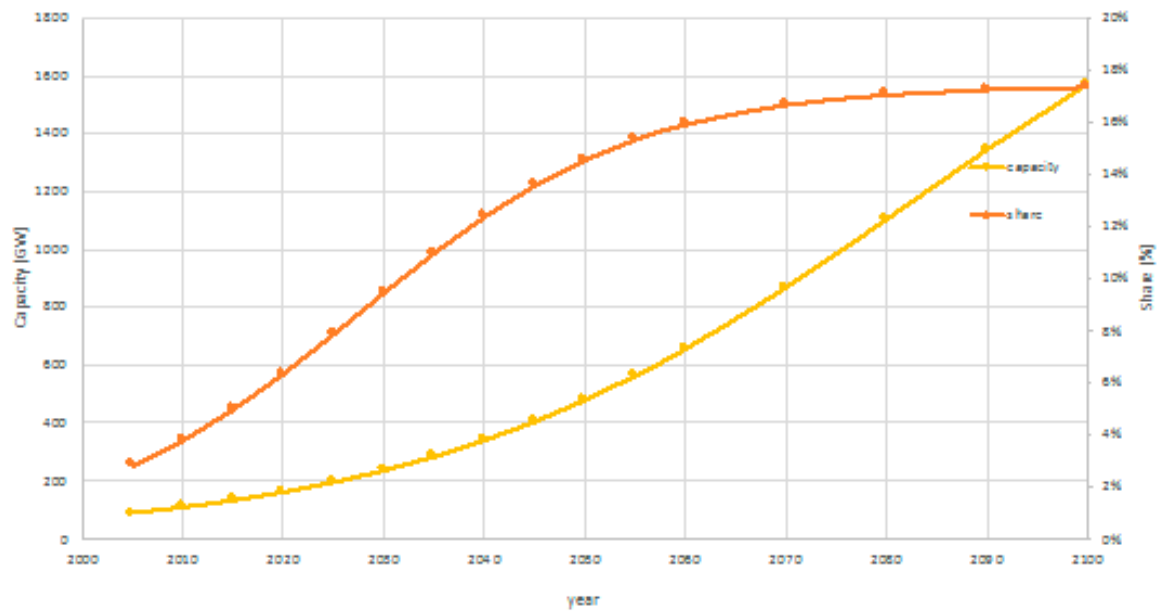

Figure 4. Europe PV technology capacity development based on the reference scenario of WITCH until the year 2100 (own work).

The Europe's PV energy generation will increase significantly until the year 2100-to about $20 \mathrm{EJ} / \mathrm{yr}$ (REMIND) or $8.5 \mathrm{EJ} / \mathrm{yr}$ (WITCH) which will contribute to over $58 \%$ (REMIND) or 17\% (WITCH) of overall generated energy (Table 7). 
Table 6. Parameters calculated for the S-shaped PV curves (Figures 3 and 4).

\begin{tabular}{ccccccccc}
\hline Criteria & \multicolumn{4}{c}{ Remind } & \multicolumn{4}{c}{ Witch } \\
\hline \multirow{2}{*}{ Capacity [GW] } & $L$ & $k$ & $t_{0}$ & $r$ & $L$ & $k$ & $t_{0}$ & $r$ \\
& 5525 & 0.06 & 2065 & 0.99 & 2,418 & 0.041 & 2085 & 0.997 \\
\hline \multirow{2}{*}{ Share [\%] } & $L$ & $k$ & $t_{0}$ & $r$ & $L$ & $k$ & $t_{0}$ & $r$ \\
& 73 & 0.11 & 2028 & 0.99 & 17.7 & 0.105 & 2020 & 0.969 \\
\hline
\end{tabular}

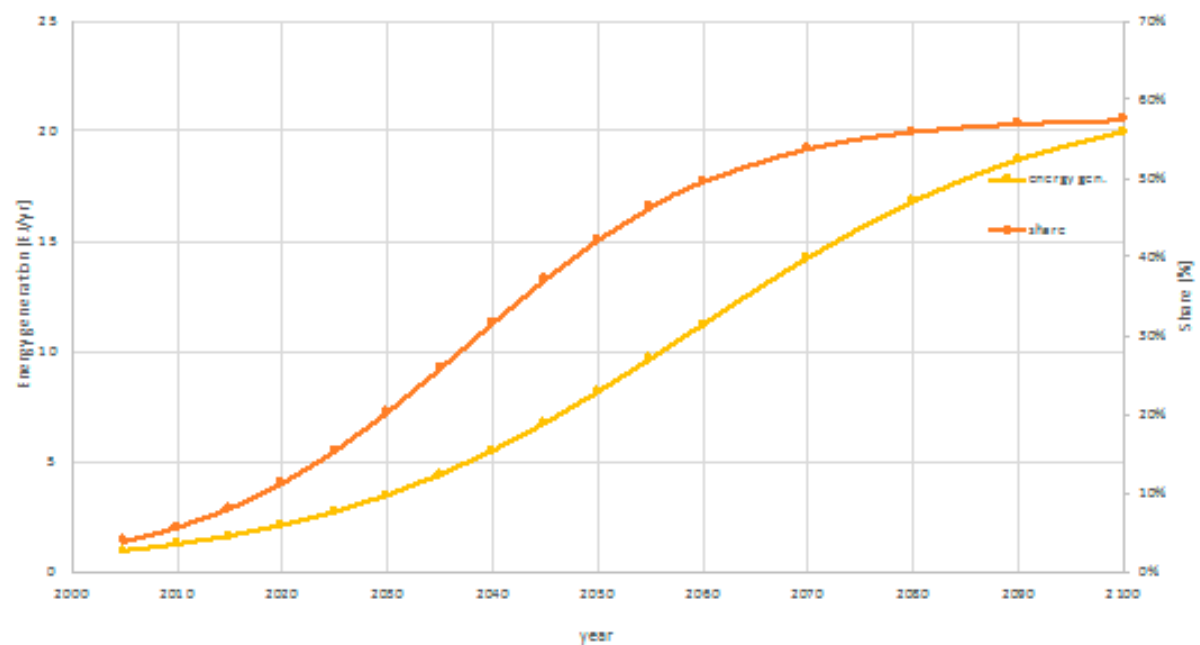

Figure 5. Europe PV technology energy generation development based on the reference scenario of REMIND until the year 2100 (own work).

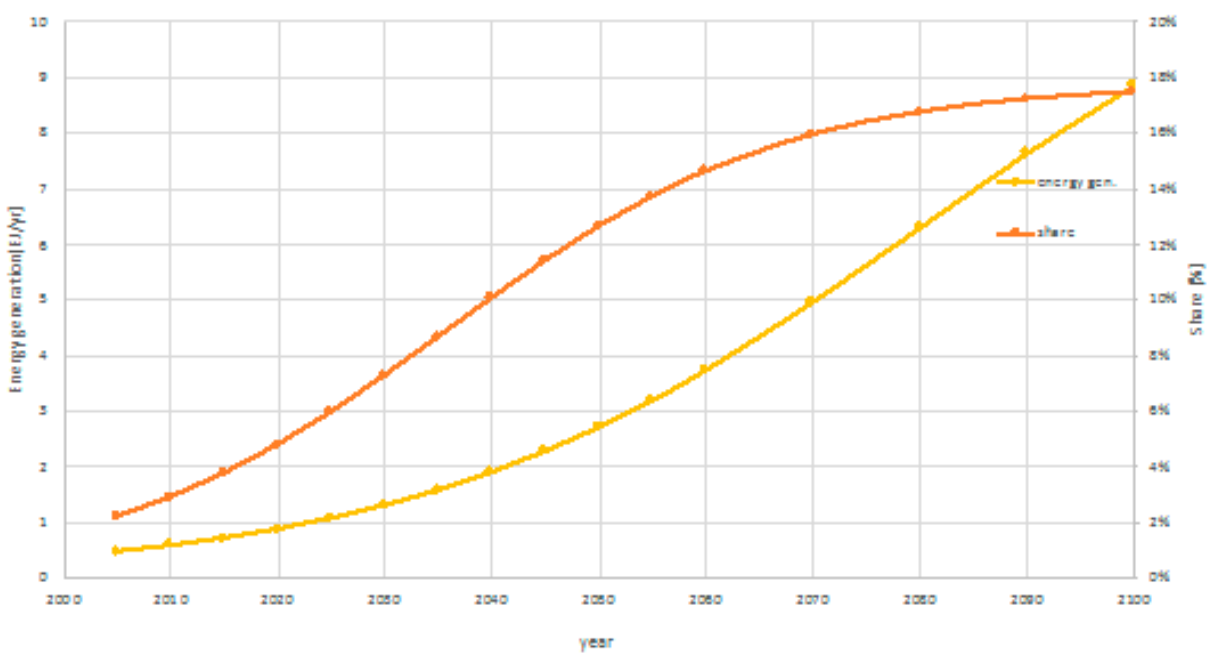

Figure 6. Europe PV technology energy generation development based on the reference scenario of WITCH until year 2100 (own work).

Table 7. Parameters calculated for the S-shaped curves (Figures 5 and 6).

\begin{tabular}{ccccccccc}
\hline Criteria & \multicolumn{4}{c}{ Remind } & \multicolumn{4}{c}{ Witch } \\
\hline Energy generation & $L$ & $k$ & $t_{0}$ & $r$ & $L$ & $k$ & $t_{0}$ & $r$ \\
[EJ/yr] & 21.9 & 0.0573 & 2059 & 0.99 & 13.09 & 0.042 & 2082 & 0.997 \\
\hline \multirow{2}{*}{ Share [\%] } & $L$ & $k$ & $t_{0}$ & $r$ & $L$ & $k$ & $t_{0}$ & $r$ \\
& 58.1 & 0.0795 & 2038 & 0.99 & 17.78 & 0.063 & 2036 & 0.983 \\
\hline
\end{tabular}




\subsubsection{Wind Technology}

The REMIND model predicts Europe's continuous expansion of wind capacity to the level of above 1.1 TW by 2100, and according to WITCH, it will increase to above 2.7 TW which will contribute to almost $20 \%$ and $30 \%$ of the whole installed capacity, respectively (Table 8 ).

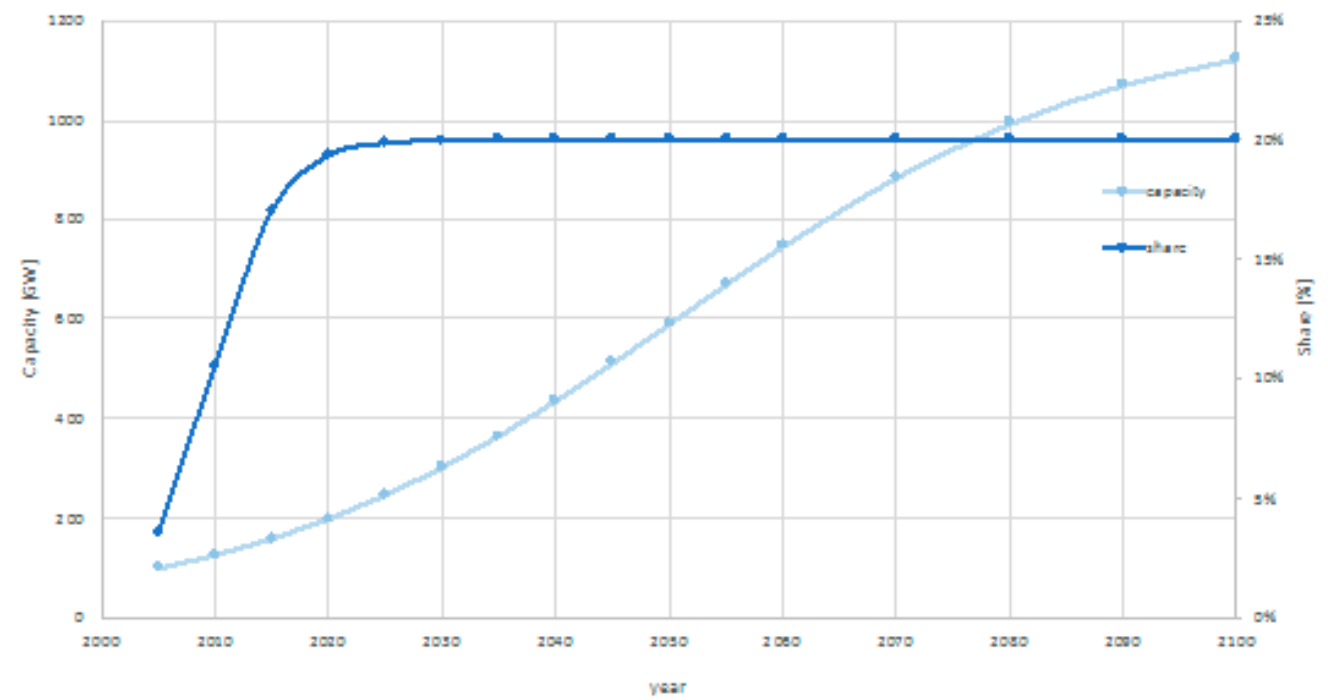

Figure 7. Europe wind technology capacity development based on the reference scenario based on the reference scenario of REMIND until the year 2100 (own work).

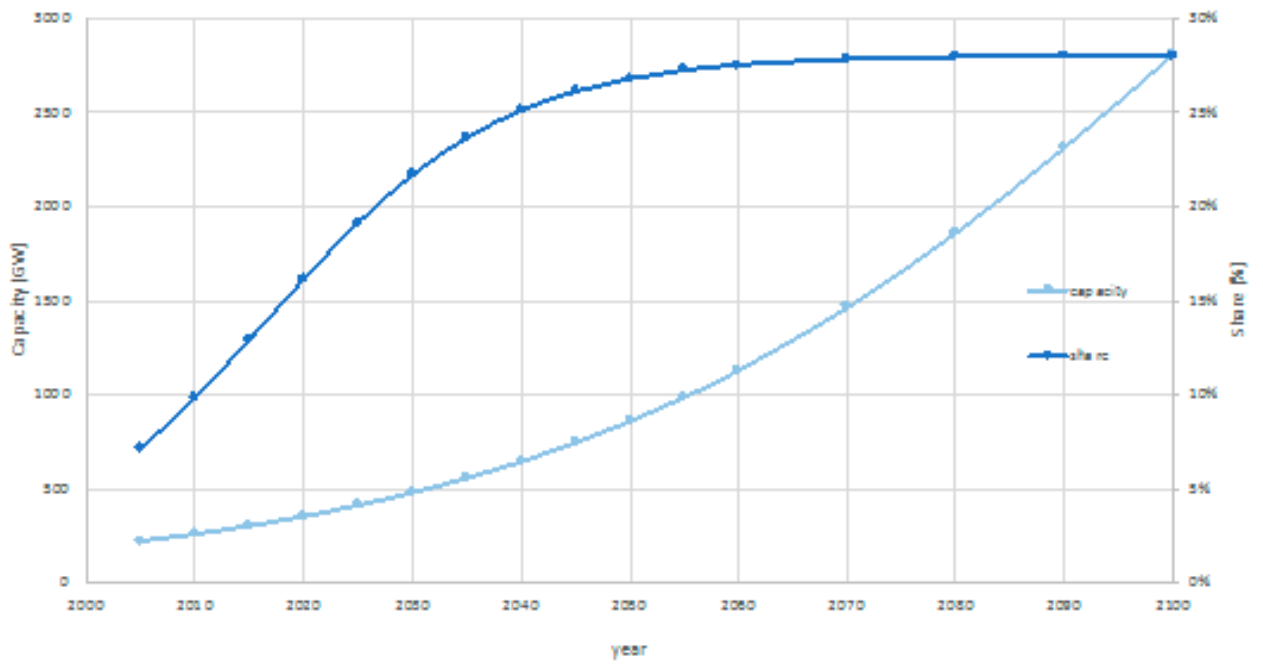

Figure 8. Europe wind technology capacity development based on the reference scenario based on the reference scenario of WITCH until the year 2100 (own work).

Table 8. Parameters calculated for the S-shaped wind technology curves (Figures 7 and 8).

\begin{tabular}{ccccccccc}
\hline Criteria & \multicolumn{4}{c}{ Remind } & \multicolumn{5}{c}{ Witch } \\
\hline \multirow{2}{*}{ Capacity [GW] } & $L$ & $k$ & $t_{0}$ & $r$ & $L$ & $k$ & $t_{0}$ & $r$ \\
& 1207.4 & 0.053 & 2051 & 0.996 & $1,377,400$ & 0.025 & 2349 & 0.993 \\
\hline \multirow{2}{*}{ Share [\%] } & $L$ & $k$ & $t_{0}$ & $r$ & $L$ & $k$ & $t_{0}$ & $r$ \\
& 20 & 0.334 & 2009 & 0.972 & 29.5 & 0.248 & 2013 & 0.971 \\
\hline
\end{tabular}

European development of wind power technology based on energy generation is represented by a curve similar to a linear one-the increase is very uniform. About 11 EJ (REMIND) or 28 EJ (WITCH) 
of energy will be generated in 2100. The wind technology development in Europe is similar to that of PV technology - the energy generation is still rising in year 2100, while the saturation level has already been reached in 2070 (about 30\%—REMIND, 50\%—WITCH) (Table 9).

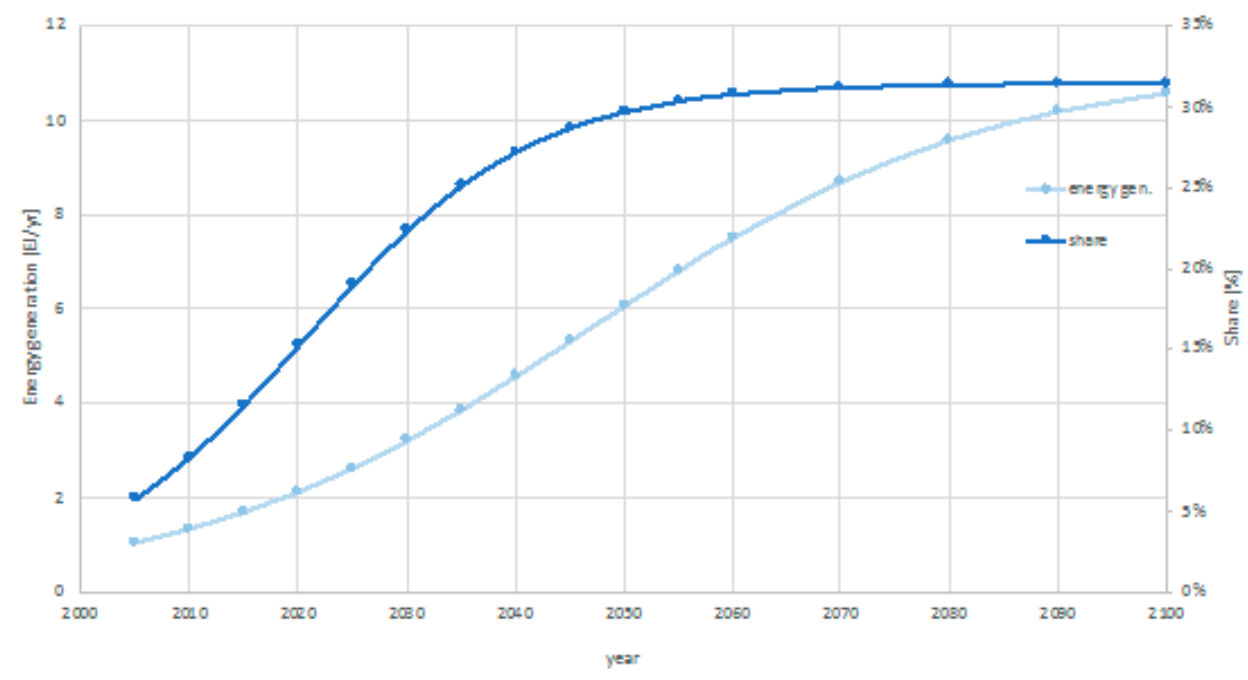

Figure 9. Europe Wind technology energy generation development based on Reference Scenario of REMIND until year 2100 (own work).

Table 9. Parameters calculated for the S-shaped wind technology curves (Figures 9 and 10).

\begin{tabular}{ccccccccc}
\hline Criteria & \multicolumn{4}{c}{ Remind } & \multicolumn{4}{c}{ Witch } \\
\hline Energy generation & $L$ & $k$ & $t_{0}$ & $r$ & $L$ & $k$ & $t_{0}$ & $r$ \\
[EJ/yr] & 11.16 & 0.05 & 2047 & 0.99 & 49.58 & 0.034 & 2092 & 0.992 \\
\hline \multirow{2}{*}{ Share [\%] } & $L$ & $k$ & $t_{0}$ & $r$ & $L$ & $k$ & $t_{0}$ & $r$ \\
& 31 & 0.10 & 2021 & 0.99 & 52.8 & 0.082 & 2024 & 0.952 \\
\hline
\end{tabular}

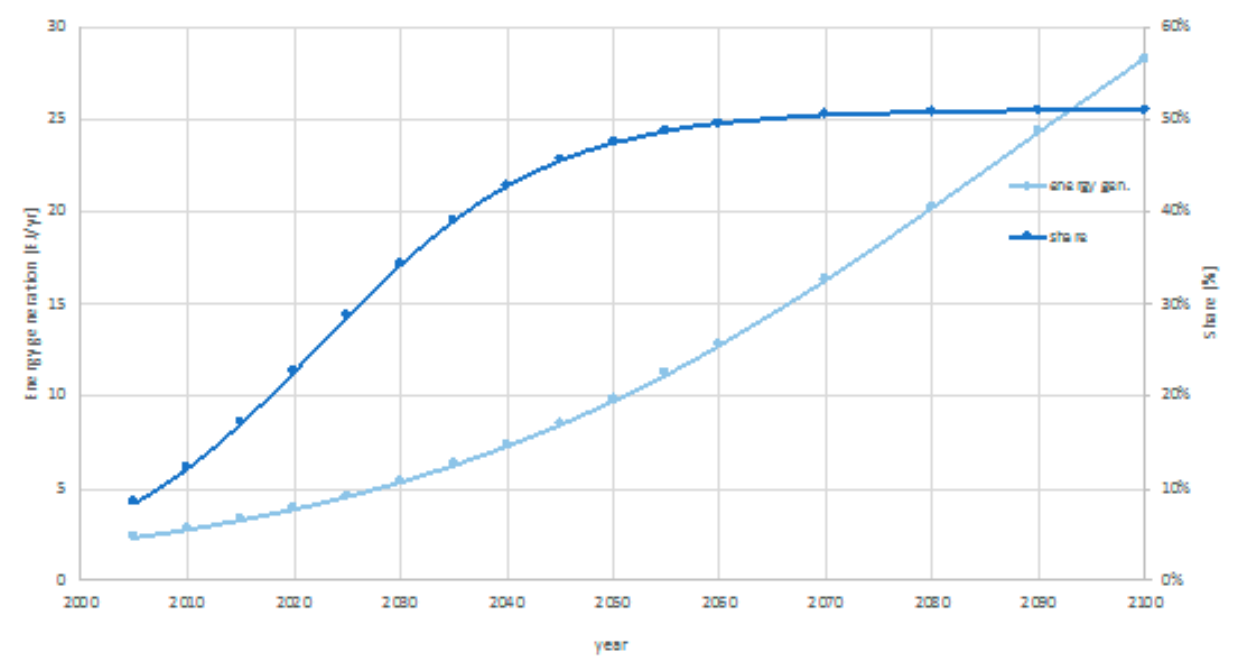

Figure 10. Europe Wind technology energy generation development based on Reference Scenario of WITCH until year 2100 (own work).

\subsubsection{Wind and PV—Comparison with Other Reference Scenarios}

Figures 11-14 show the point data from the reference scenarios for the two models discussed above against the two other models, namely WEM (World Energy Outlook 2017) and PRIMES ver. 4 Energy Model, with approximation to the S-curve formula (3) in the time domain. 


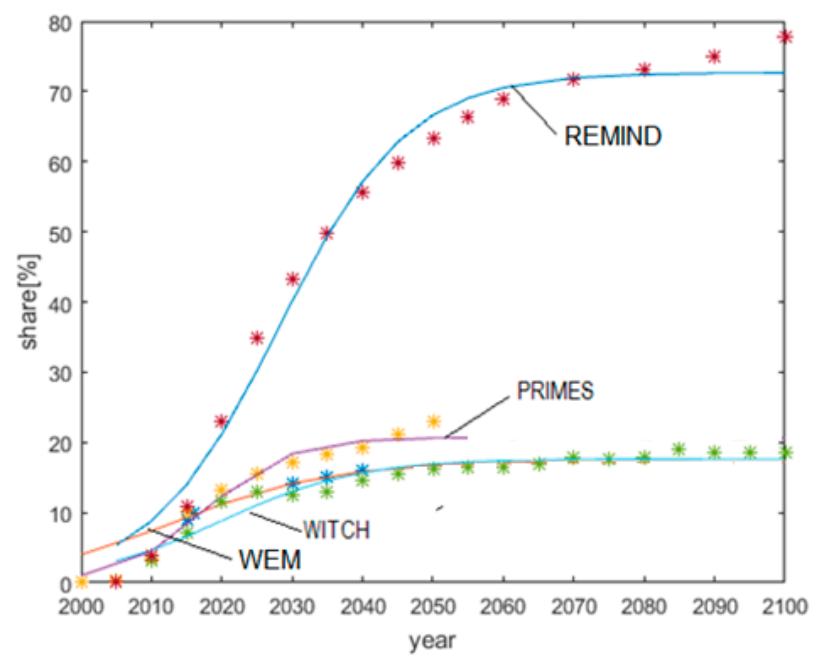

Figure 11. Reference scenarios for WEM, WITCH, PRIMES and REMIND programs for Europe's solar PV capacity share (own work).

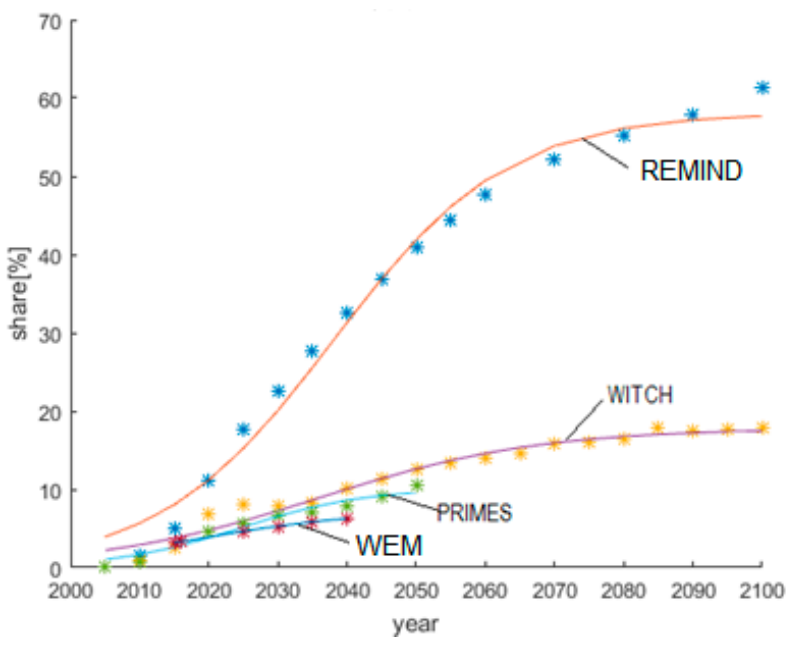

Figure 12. Reference scenarios for WEM, WITCH, PRIMES and REMIND programs for Europe's solar PV power energy generation share (own work).

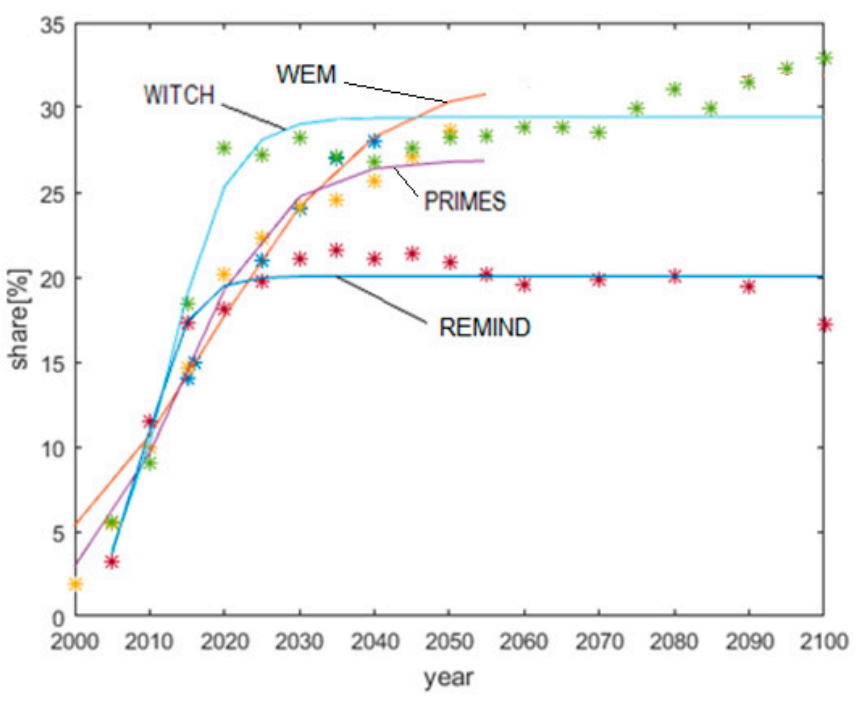

Figure 13. Reference scenarios for WEM, WITCH, PRIMES and REMIND programs for Europe's wind power capacity share (own work). 


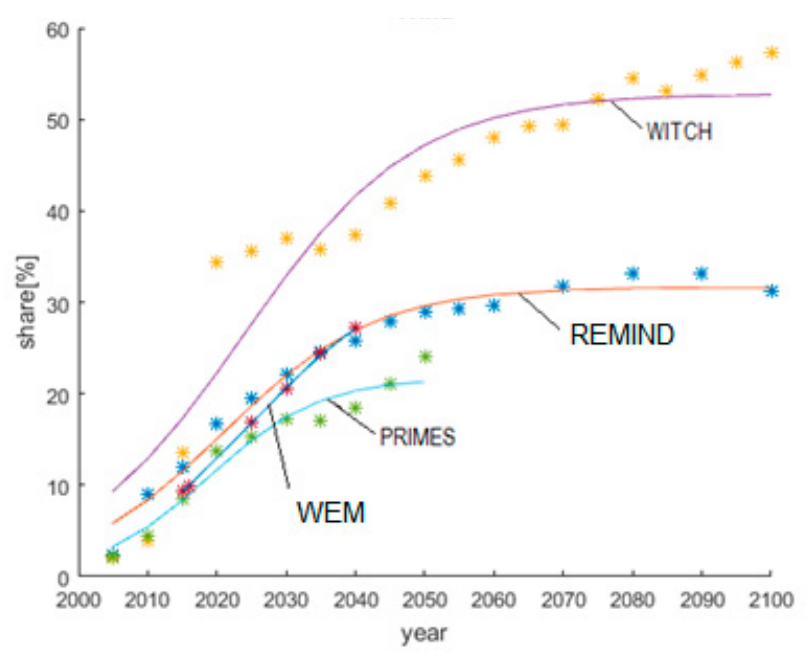

Figure 14. Reference scenarios for WEM, WITCH, PRIMES and REMIND programs for Europe's wind power energy generation share (own work).

The development of solar PV technology in Europe clearly differs depending on a program from which the input data have been taken. The highest values of installed capacity share in Europe come from the REMIND model. The constant increase, reaching about $23 \%$ in year 2020 , then $44 \%$ in $2030,57 \%$ in 2040 and $62 \%$ in 2050 . The shares keep increasing even further, which could lead to the conclusion, that Europe's energy system will be completely dominated by this source of energy. However, the remaining programs do not predict such a huge development. According to PRIMES, in year 2050 the PV share is going to be $20 \%$ and it remains stable. The WEM and WITCH model curves are very similar and basically overlap each other since year 2040. According to them, in year 2050 the capacity share of solar PV in Europe's energy system is going to be $16 \%$. The S-shape is less visible for these two programs, although the blue and purple curves representing PRIMES and REMIND data, follow the characteristic S-shape (Figure 11).

The development of solar PV technology described by energy production is similar to the one presented by cumulative capacity. The REMIND model again is the most optimistic - the EU share of PV energy production reaches $42 \%$ of global and grows up to $60 \%$ in 2100 . It is interesting, because the installed capacity for this technology is expected to be over $70 \%$ for that period-therefore, these two factors are not exactly interdependent. According to WITCH, PV share in Europe is going to be $13 \%$ in 2050 and $18 \%$ in 2100. For energy generation the forecast of PRIMES is worse that WITCH's (in comparison to the curves generated for capacity). In 2050 the PV share is only $11 \%$ in this scenario, while for WEM it is even lower (Figure 12).

The comparison of S-shaped curves representing the share of installed capacity in Europe for WEM, PRIMES, WITCH and REMIND programs shows that the scenarios do not differ significantly in case of wind power (Figure 13). The REMIND model predicts the lowest development of this technology - the Europe's wind power share is slowly increasing to $20 \%$ until year 2030, but later it slightly decreases. It can be caused by the development of other technologies, however until year 2050 the tendency is rather upward. PRIMES is a little bit more optimistic-the share of wind rises to $26 \%$ in year 2050, and then it remains stable. The WITCH program shows a considerable increase of wind share to $28 \%$ in 2020 , then it remains stable. The best reference scenario comes from WEM-wind energy shares continuously grow until year 2080, when they reach $32 \%$, which is the highest value from all included scenarios. In the case of wind energy, the S-shape can be hardly seen and is only present on the orange curve describing data from WEM.

The distribution of curves showing the shares of wind energy production in Europe clearly differs from the ones for capacity. The most optimistic scenario is created by WITCH in this case. This program predicts that in year 2050 the Europe's share in energy production coming from wind technology is going to be $43 \%$ and this number is going to rise up to $55 \%$ in 2100 . Much lower values appear 
according to REMIND, where in 2050 the share is nearly $30 \%$, but is going to keep rising. The WEM scenario shows a bit steeper shape of the logistic curve, so even though the data end on year 2040, from the S-shape behaviour, we can assume that in year 2050 this curve would be higher than the REMIND one. It is surprising that the WEM scenario is the best in case of capacity, while in the energy production model the values are not that high. The lowest wind share based on energy production is represented by PRIMES-it reaches $24 \%$ in 2050 and based on a shape remains quite stable in the following years (Figure 14).

\section{Discussion}

Since solar PV and wind are the most promising technologies (together they are expected to produce more than $80 \%$ of global energy in some scenarios till 2100), this paper has been focused on the two technologies only. The comparison of data collected from different sources shows that the projected values of capacity, electricity generation and cost of PV and wind technologies can significantly differ across various sources as well as various scenarios. However, there exists one dependency-the more recent scenario, the higher values of capacity and electricity generation are expected in the future.

The learning curves created for PV show very high convergence between historical data and calculated values. The unit cost of c-Si modules is expected to decrease significantly during the following years, reaching values lower than 1 USD/W. If the cumulative global capacity in 2050 will be as projected-6200 GW, the price should decrease even to $0.2 \mathrm{USD} / \mathrm{W}$ (compared to $0.54 \mathrm{USD} / \mathrm{W}$ today). The learning curves representing wind power development do not cover historical data as ideally as in the case of PV, however they stay close to these values, so they can serve as the appropriate mapping of the situation. The levelized cost of wind technology in 2050 will be $44 \mathrm{USD} / \mathrm{MWh}$, while the cumulative capacity reaches $5940 \mathrm{GW}$ worldwide (compared to 66 USD/MWh in 2018). In the paper [59] the review of different learning curves has been made and the meta-analysis of LR for wind power technology. The result of this study is that the presence of learning spillovers due to geographical domain of learning, influences LR to a large extent. Another conclusion made by them is that integrating additional factors like R\&D lowers the LR in comparison to the studies based on single-factor curves.

The second way of long-term energy modeling is the S-shaped logistic curve. Worldwide, both PV and wind power are in the maturity level which means that this technology has already significantly developed but still some improvement can be made as the saturation point has not been reached yet. The logistic curves for Europe behave similarly for PV and wind technologies-they both reach the saturation level in case of share, but taking into consideration only capacity or electricity generation, they are still in the maturity stage. According to analyzed scenarios, the shares in both the total installed capacity in EU-28 and in energy generation will be stabilizing since around 2060-2070 in case of PV and around 2040-2050 in the case of wind, but with a quantitative increase in capacity and energy generation for both technologies still being observed.

There is a qualitative convergence of most scenarios concerning the saturation targets (after 2050) for the share of PV technology capacity (EU-28) at around 20\% (between 1.5 TW and 3 TW by volume) and wind at around $30 \%$ (between 1 TW and 4 TW by volume). There is a significant discrepancy in the case of the REMIND model which provides for a share of more than 70\% of PV technology capacity (up to 8 TW in volume).

The share of energy generation in the EU-28 reaches saturation for PV at up to $20 \%$, and only the REMIND model predicts a level of up to $60 \%$. In the case of wind technologies, the scenarios project saturation in the range of $20-34 \%$, only the WITCH model predicts a level of up to $50 \%$. It is noted that with regard to model outcomes in terms of energy production and available capacity of PV and wind technology in Europe, the WITCH scenarios overestimate wind energy in comparison to other models, while the REMIND scenarios overestimate PV.

IRENA [41] predicts that by 2050, all countries can substantially increase the proportion of RES energy in their total final energy consumption (TFEC), for example in the EU, the share could grow 
from about $17 \%$ to over $70 \%$. However, since a technology change is assumed to be endogenous in many models, the modeling results should not be treated as unequivocal because there are many factors influencing the development. There are also aspects which are difficult to predict, like some breakthrough events, new policies or natural resources shortages. Another issue is the fact that some factors can influence each other, for example prices and demand are interdependent, and sometimes it can be difficult to judge which one was the cause and which the result. Fortunately, energy models try to take into account such relations and for now the ones based on learning curves may be treated as those producing the very reliable results.

The logistic function turns out to be a useful model used in scenarios predicting the diffusion of PV and wind technologies over time. This is proved by the high matching ratios (Pearson factor $r>0.9$ ) of the selected logistic curve approximating the numerical data from the analyzed scenarios. The models used in the analyzed scenarios are therefore similar, differences in numerical results (different target values for the share of PV and wind in European energy mix) may result from a different assessment of the expected effects of energy policy measures. It is natural that the standard deviations of the scenario versions increase with the prediction horizon as they illustrate the target differences in the effects of the implementation of the various policies affecting the energy sector. It is characteristic that each version of the scenarios, also assuming no political stimulation, foresees a significant development of both wind and PV generation technologies in Europe and worldwide.

Divergences between the versions of scenario increase with the length of the projection period, illustrating the impact of the chosen policy on the effect of increasing the use of RES. In scenarios with quantitative numerical data results, a clear division of wind generation technologies into onand off-shore technologies is often lacking. It would be interesting to model the development of PV technologies, divided into commercial-large-scale and prosumer-installations in buildings.

Scenarios predict a steadily growing trend (for PV and wind) technologies in both installed capacity and quantitative energy generation in Europe. This is due to the expected continuous increase in clean energy demand in Europe. On the basis of the data from the analyzed reference scenario models, the shares of the both technologies capacity and generation in the EU-28 are expected to stabilize (close to saturation), which will take place no earlier than in 2040. It will happen despite the continuous increase in the amount of both capacity and energy production for the both technologies, modeled also by a logistic function.

The analysis shows sensitivity of the curves to initial cost data. It is obvious that decreasing specific price and increasing prevalence of technology are correlated which can be quantitatively modeled by means of learning curves. However, the models discussed in the literature have limitations. Policies can stimulate and accelerate the natural development and availability of technology by indirectly influencing the costs. It has an impact on the time at which a technology can achieve the adequate market saturation. It is clearly projected by the S-shaped curves.

\section{Conclusions}

Large-scale energy-economy models give us a basic understanding of the role that wind and solar can play for power sector decarbonization, but future, highly detailed analyzes with an explicitly dynamic approach are necessary to understand the timing issues and coordination needs of managing the transformation towards a power system with high levels of variable renewables, e.g., wind or solar PV. The expected increase of interactions between the different energy system sectors, e.g., power, heat, gas, and end-use sectors, has not been sufficiently analyzed in previous EU-scale scenarios, and thus needs detailed explorations to inform policy-makers and stakeholders about expected synergies and possible obstacles.

Learning curves are global, as the market for new technologies is global, while logistic curves of technology development relate to a selected area. Learning curves operate on complex econometric models and assumptions based on the most reliable data available. According to the model results, logistic S-sharped curves visualize well the spread of technology over time. Their accuracy depends 
on many factors, among others, on ambition of decarbonization policy, emerging of breakthrough technologies, energy prices and industrial strategies.

Key results of the analysis are new insights into the plausibility of future deployment scenarios in different sectors, informed by the analysis of historical dynamics of technology diffusion, using to the extent possible consistent metrics. For example, the results can be used in cost benefit analysis of policies and assessment of the dynamics of key technologies over time in energy-climate national energy plans.

The main limitations of the one-factor experience curve application can be divided into two categories: theoretical concept and empirical data. The learning models used for energy technology analysis have key practical and conceptual limitations since they are used for projection but use the historical data. Therefore, they are based on the main rules and characteristics of the past progress of technology. Such approach may be doubtful as some technologies, especially the emerging ones, e.g., $\mathrm{PV}$ or wind, evolve typically through several development stages. Therefore, from theoretical point of view, their development is likely to differ from the past progress.

Even though two-factor learning curves are considered to give more precise results, their use is possible only when specific data are available what in the majority of cases does not happen. In many two-factor models in the literature the data are in the form of short time-series.

This article, based on the classical approach, presents learning curves of PV and wind technology, showing possible relations of specific cost (available power and energy respectively) to cumulated capacity. The study has been based on selected data only and does not discuss a full spectrum of possible variations of input variables. It does not also deepen the uncertainties related to unpredictable change of different factors which did not occur in the past and may happen in the future.

The diffusion models presented fall into the category of exogenous models, whereas in reality the technological change is not an exogenous process. It leads to taking autonomous assumptions of cost reduction in time or capacity/efficiency improvement. In this respect, endogenous models perform better since they take into account additional factors like policies, market and price conditions, regulations, economies of unit scale and manufacturing scale, environmental issues, learning through R\&D or public expectations.

Fundamentally, there are two opposing forces influencing the deployment of wind and solar in scenarios: on the one side the evolution of capital costs, and on the other side integration challenges. Energy-economy models calculate scenarios of energy use and technology deployment based on techno-economic parameters, most importantly capital costs, operation \& maintenance costs, efficiencies, capacity factors, and lifetimes. In principle, these techno-economic parameters can be easily extracted from engineering studies and reports about costs from existing power plants. Modelers have decades of experience of representing power plants in their models, and for mature technologies like coal or gas power plants, costs and efficiencies are relatively stable. Thus, the 3-9 years time lag between prices observed in real markets and the prices represented in published scenarios (1-3 years until technical reports make the market prices available for modelers, 1-3 years for modelers to update the numbers in their models, 1-3 years until the scenarios are finalized and published) did not matter much in earlier times [56].

However, for newly evolving technologies like wind and solar power, the fast technological learning poses a challenge for modeling: PV prices have dropped by more than $80 \%$ over a decade, thus cost assumptions in large-scale models can substantially lag behind the real cost evolution.

Even more challenging is the future evolution of technology costs. For PV and wind, the concept of learning-by-doing costs reduce by a certain factor for each doubling of installed capacity-seems to describe past cost evolution relatively well and is thus often applied for future costs. Many IAMs and energy-economy-models assume exogenous price evolutions based on simple extrapolation of past deployment. However, many countries have implemented very strong support policies for renewable energies, thereby increasing deployment much beyond a simple extrapolation of past deployment, 
which leads to strong cost reductions that by far outstripped the cost reductions expected in the scenarios [56].

In the future the analysis of the dynamics of technologies in modeling, roadmaps and scenarios may focus on a consistent multifactor analysis of the main parameters of the dynamics (pace of diffusion and extent of diffusion in particular markets). Also, analysis of other main regions for world's energy future, e.g., China, the US or India, should be researched. Diffusion models can be extended to two-parameter models to better learn the driving forces of technology development if only suitable data are available. A change of methodology, e.g., to regression functions for long-term modeling, seems also attractive.

Author Contributions: Conceptualization, T.S.; methodology, J.W.; software, S.B.; validation, T.S. and S.B.; writing — original draft preparation, T.S. and J.W.; writing—-review and editing, T.S. and S.B.; supervision, T.S.

Funding: This research was funded by the European Union's Horizon 2020 Research and Innovation Programme under Grant Agreement No: 730403, project INNOPATHS: Innovation pathways, strategies and policies for the Low-Carbon Transition in Europe.

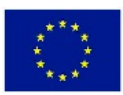

Conflicts of Interest: The authors declare no conflict of interest.

$\begin{array}{ll}\text { Abbreviations } \\ \text { EUR } & \text { The eurozone currency } \\ \text { IAM } & \text { Integrated Assessment Modeling } \\ \text { IEA } & \text { International Energy Agency } \\ \text { IRENA } & \text { International Renewable Energy Agency } \\ \text { LR } & \text { Learning rate } \\ \text { OECD } & \text { Organization for Economic Co-operation and Development } \\ \text { PRIMES } & \text { Price-Induced Market Equilibrium System } \\ \text { PV } & \text { Photovoltaics } \\ \text { R\&D } & \text { Research and development } \\ \text { REmap } & \text { Renewable Energy Roadmaps } \\ \text { RES } & \text { Renewable Energy Sources } \\ \text { SSP } & \text { Shared Socioeconomic Pathways } \\ \text { USD } & \text { US Dollars (currency) } \\ \text { WEO } & \text { World Energy Outlook } \\ \text { WEM } & \text { World energy Model } \\ \text { WITCH } & \text { World Induced Technical Change Hybrid } \\ \text { REMIND } & \text { Regionalized Model of Investments and Development }\end{array}$

\section{References}

1. Elshurafa, A.M.; Albardi, S.R.; Bigerna, S.; Bollino, C.A. Estimating the learning curve of solar PV balance-of-system for over 20 countries: Implications and policy recommendations. J. Clean. Prod. 2018, 196, 122-134. [CrossRef]

2. Furlan, C.; Mortarino, C. Forecasting the impact of renewable energies in competition with non-renewable sources. Renew. Sustain. Energy Rev. 2018, 81, 1879-1886. [CrossRef]

3. Wene, C.-O. Quantum modelling of the learning curve. Futures 2018, 103, 123-135. [CrossRef]

4. Junginger, M.; Faaij, A.; Turkenburg, W. Global experience curves for wind farms. Energy Policy 2005, 33, 133-150. [CrossRef]

5. Rogers, E. Diffusion of Innovations; The Free Press: New York, NY, USA, 1983.

6. Meade, N.; Islam, T. Modelling and forecasting the diffusion of innovation-A 25-year review. Int. J. Forecast. 2006, 22, 519-545. [CrossRef] 
7. Bolwig, S.; Bazbauers, G.; Klitkou, A.; Lund, P.D.; Blumberga, A.; Gravelsins, A.; Blumberga, D. Review of modelling energy transitions pathways with application to energy system flexibility. Renew. Sustain. Energy Rev. 2019, 101, 440-452. [CrossRef]

8. Zhang, N.; Lu, Y.; Chen, J. Development of An Innovation Diffusion Model for Renewable Energy Deployment. Energy Procedia 2018, 152, 959-964. [CrossRef]

9. Kucharavy, D.; De Guio, R. Appliation of S-shaped curves. Proc. Eng. 2011, 9, 559-572. [CrossRef]

10. Pavlidou, A. Diffusion of the Diffusion Curve: A Research on the S-Curves in Relation to Technological Clusters; Utrecht University: Utrecht, The Netherlands, 2010.

11. Neij, L. Cost dynamics of wind power. Energy 1999, 24, 375-389. [CrossRef]

12. Samadi, S. The experience curve theory and its application in the field of electricity generation-A literature review. Renew. Sustain. Energy Rev. 2018, 82, 2346-2364. [CrossRef]

13. Junginger, M.; van Sark, W.; Kahouli-Brahmi, S.; Schaeffer, G.J. Chapter 2-The experience curve approach: History, methodological aspects and applications. In Technological Learning in the Energy Sector: Lessons for Policy, Industry and Science; Edward Elgar Publishing: Cheltenham, UK, 2010.

14. Grosse, E.H.; Glock, C.H.; Müller, S. Production economics and the learning curve: A meta-analysis. Int. J. Prod. Econ. 2015, 170, 401-412. [CrossRef]

15. Weiss, M.; Junginger, M.; Patel, M.K.; Blok, K. A review of experience curve analyses for energy demand technologies. Technol. Forecast. Soc. Chang. 2010, 77, 411-428. [CrossRef]

16. Witajewski-Baltvilks, J.; Verdolini, E.; Tavoni, M. Bending the learning curve. Energy Econ. 2015, 52, 586-599. [CrossRef]

17. Pan, H.; Köhler, J. Technological change in energy systems: Learning curves, logistic curves and input-output coefficients. Ecol. Econ. 2007, 63, 749-758. [CrossRef]

18. Ferioli, F.; Schoots, K.; Van Der Zwaan, B. Use and limitations of learning curves for energy technology policy: A component-learning hypothesis. Energy Policy 2009, 37, 2525-2535. [CrossRef]

19. De La Tour, A.; Glachant, M.; Ménière, Y. Predicting the costs of photovoltaic solar modules in 2020 using experience curve models. Energy 2013, 62, 341-348. [CrossRef]

20. Jimenez, M.; Franco, C.J.; Dyner, I. Diffusion of renewable energy technologies: The need for policy in Colombia. Energy 2016, 111, 818-829. [CrossRef]

21. Hong, S.; Chung, Y.; Woo, C. Scenario analysis for estimating the learning rate of photovoltaic power generation based on learning curve theory in South Korea. Energy 2015, 79, 80-89. [CrossRef]

22. Hayashi, D.; Huenteler, J.; Lewis, J. Gone with the wind: A learning curve analysis of China's wind power industry. Energy Policy 2018, 120, 38-51. [CrossRef]

23. Yeh, S.; Rubin, E.S. A review of uncertainties in technology experience curves. Energy Econ. 2012, 34, 762-771. [CrossRef]

24. Pfeiffer, B.; Mulder, P. Explaining the diffusion of renewable energy technology in developing countries. Energy Econ. 2013, 40, 285-296. [CrossRef]

25. Freitas, I.M.B.; Dantas, E.; Iizuka, M. The Kyoto mechanisms and the diffusion of renewable energy technologies in the BRICS. Energy Policy 2012, 42, 118-128. [CrossRef]

26. Verdolini, E.; Vona, F.; Popp, D. Bridging the gap: Do fast-reacting fossil technologies facilitate renewable energy diffusion? Energy Policy 2018, 116, 242-256. [CrossRef]

27. Kumar, R.; Agarwala, A. Renewable energy technology diffusion model for techno-economics feasibility. Renew. Sustain. Energy Rev. 2016, 54, 1515-1524. [CrossRef]

28. Horbach, J.; Rammer, C. Energy transition in Germany and regional spill-overs: The diffusion of renewable energy in firms. Energy Policy 2018, 121, 404-414. [CrossRef]

29. Corsatea, T.D.; Giaccaria, S.; Covrig, C.-F.; Zaccarelli, N.; Ardelean, M. RES diffusion and R\&D investments in the flexibilisation of the European electricity networks. Renew. Sustain. Energy Rev. 2016, 55, 1069-1082.

30. Comin, D.; Mestieri, M. Technology Diffusion: Measurement, Causes, and Consequences. In Handbook of Economic Growth; Elsevier: Amsterdam, The Netherlands, 2014; Volume 2, pp. 565-622.

31. Helm, C.; Mier, M. On the efficient market diffusion of intermittent renewable energies. Energy Econ. 2019, 80, 812-830. [CrossRef]

32. Harris, T.M.; Devkota, J.P.; Khanna, V.; Eranki, P.L.; Landis, A.E. Logistic growth curve modeling of US energy production and consumption. Renew. Sustain. Energy Rev. 2018, 96, 46-57. [CrossRef] 
33. Hansen, J.; Narbel, P.; Aksnes, D. Limits to growth in the renewable energy sector. Renew. Sustain. Energy Rev. 2017, 70, 769-774. [CrossRef]

34. Radomes, A., Jr.; Arango, S. Renewable energy technology diffusion: An analysis of photovoltaic-system support schemes in Medelin, Colombia. J. Clean. Prod. 2015, 92, 152-161. [CrossRef]

35. Verhulst, P.-F. Notice sur la loi queue la population suit dans son accroissement. Corresp. Math. Phys. 1838, 10, 113-121.

36. Kucharavy, D.; De Guio, R. Application of Logistic Growth Curve. Procedia Eng. 2015, 131, 280-290. [CrossRef]

37. Villanueva, D.; Feijóo, A. Comparison of logistic functions for modeling wind turbine power curves. Electr. Power Syst. Res. 2018, 155, 281-288. [CrossRef]

38. Clarke, L.; Jiang, K. Assessing Transformation Pathways. In Climate Change 2014: Mitigation of Climate Change. Contribution of Working Group III to the Fifth Assessment Report of the Intergovernmental Panel on Climate Change; Edenhofer, O., Pichs-Madruga, R., Eds.; Cambridge University Press: Cambridge, UK; New York, NY, USA, 2014.

39. Luderer, G.; Krey, V.; Calvin, K.; Merrick, J.; Mima, S.; Pietzcker, R.; Van Vliet, J.; Wada, K. The role of renewable energy in climate stabilization: Results from the EMF27 scenarios. Clim. Chang. 2014, 123, 427-441. [CrossRef]

40. International Energy Agency. World Energy Outlook 2016. Available online: https://www.iea.org/newsroom/ news/2016/november/world-energy-outlook-2016.html (accessed on 20 October 2019).

41. International Renewable Energy Agency. IRENA Global Energy Transformation a Roadmap to 2050 (2018 Edition). Available online: https://www.irena.org//media/Files/IRENA/Agency/Publication/2018/Apr/ IRENA_Report_GET_2018.pdf (accessed on 20 October 2019).

42. Creutzig, F.; Agoston, P.; Goldschmidt, J.C.; Luderer, G.; Nemet, G.; Pietzcker, R.C. The underestimated potential of solar energy to mitigate climate change. Nat. Energy 2017, 2, 17140. [CrossRef]

43. REN21. Renewables Global Status Report 2017, Global Status Report; Renewable Energy Policy Network for the 21st Century; REN21 Secretariat: Paris, France, 2017.

44. International Energy Agency. Technology Roadmap Wind Energy 2013. Available online: https://webstore. iea.org/technology-roadmap-wind-energy-2013 (accessed on 20 October 2019).

45. International Energy Agency. Technology Roadmap Solar Photovoltaic Energy 2010. Available online: https://webstore.iea.org/technology-roadmap-solar-photovoltaic-energy-2010 (accessed on 9 October 2019).

46. International Energy Agency. How2Guide for Wind Energy-Roadmap Development and Implementation 2014. Available online: https://www.oecd.org/publications/how2guide-for-wind-energy-9789264211759-en. htm (accessed on 10 October 2019).

47. Solar Power Europe. Solar Photovoltaics Jobs \& Value Added in Europe. 2015. Available online: https: //www.solarpowereurope.org/solar-pv-jobs-value-added-in-europe (accessed on 2 May 2018).

48. International Energy Agency. Technology Roadmap Solar Photovoltaic Energy 2014. Available online: https://webstore.iea.org/technology-roadmap-solar-photovoltaic-energy-2014 (accessed on 20 October 2019).

49. International Energy Agency. World Energy Outlook 2018. Available online: https://webstore.iea.org/worldenergy-outlook-2018 (accessed on 12 October 2019).

50. International Energy Agency. World Energy Outlook 2016. Available online: https://webstore.iea.org/worldenergy-outlook-2016 (accessed on 12 October 2019).

51. BP Energy Outlook 2018. Available online: https://www.bp.com/content/dam/bp/en/corporate/pdf/energyeconomics/energy-outlook/bp-energy-outlook-2018.pdf (accessed on 5 October 2019).

52. Kersten, F.; Doll, R.; Kux, A.; Huljić, D.; Görig, M.; Müller, J.; Wawer, P. PV Learning Curves: Past and Future Drivers of Cost Reduction. In Proceedings of the 26th European Photovoltaic Solar Energy Conference and Exhibition, Hamburg, Germany, 5-9 September 2011.

53. Rubin, E.S.; Azevedo, I.M.; Jaramillo, P.; Yeh, S. A review of learning rates for electricity supply technologies. Energy Policy 2015, 86, 198-218. [CrossRef]

54. Hansen, U.; Nygaard, I.; Pedersen, M. Prospects for Investment in Large-Scale, Grid-Connected Solar Power in Africa; UNEP Riso Centre: Copenhagen, Denmark, 2014.

55. Bloomberg New Energy Finance Summit. In Proceedings of the Bloomberg New Energy Finance, New York, NY, USA, 5 April 2016. 
56. INNOPATHS: Innovation Pathways, Strategies and Policies for the Low-Carbon Transition in Europe. D1.3 Sectorial Analysis Draft Report. 2019. Available online: https://innopaths.eu/2019/09/20/1-3-innovationpathways-strategies-and-policies-for-the-low-carbon-transition-in-europe/ (accessed on 7 November 2019).

57. Model Documentation—REMIND. Available online: https://www.iamcdocumentation.eu/index.php/Model_ Documentation_-_REMIND (accessed on 5 October 2019).

58. The WITCH Model Documentation. Available online: https://www.witchmodel.org/documentation/ (accessed on 5 October 2019).

59. Lindman, Å.; Söderholm, P. Wind power learning rates: A conceptual review and meta-analysis. Energy Econ. 2012, 34, 754-761. [CrossRef]

(C) 2019 by the authors. Licensee MDPI, Basel, Switzerland. This article is an open access article distributed under the terms and conditions of the Creative Commons Attribution (CC BY) license (http://creativecommons.org/licenses/by/4.0/). 